\title{
CALASSO, Roberto. A marca do editor. Tradução de Pedro Fonseca. Belo Horizonte: Editora Âyiné, 2020.
}

\section{Lou-Ann Kleppa}

Universidade Federal de Rondônia (UNIR), Porto Velho, Rondônia / Brasil loukleppa@yahoo.com

http://orcid.org/0000-0003-0317-9440

Quem segura na mão o livro de Roberto Calasso, $A$ marca do editor, lançado em 2020 pela Editora Âyiné, perceberá que a capa e a contracapa estão invertidas: o nome do autor e o título do livro estão na quarta capa. O livro faz parte da Coleção Das Andere, ${ }^{1}$ em que essa configuração gráfica se repete. A capa é de Julia Geiser, como tantas outras capas da editora. Em entrevista à Revista Voz da Literatura (2018), a capista afirma que "meu trabalho é pesquisar, bem como retrabalhar a ubiquidade das imagens com as quais somos confrontados por meio da esfera on-line" (GEISER, 2018). As capas, que são resultado de colagens, formam a identidade visual da editora, ou seja, cada capa é um elo no catálogo da Âyiné. Coincidência ou não, a editora Adelphi pratica o que Calasso (2020, p. 20) chama de écfrase ao avesso: encontrar uma imagem que sintetize as palavras do livro, ao invés de descrever uma imagem com palavras. Segundo Calasso (2020, p. 23), as capas da Adelphi são todas colhidas de imagens existentes:

[o] objetivo é uma rede de imagens que não apenas correspondem cada uma a um único objeto (o livro para o qual são usadas), mas que correspondem entre si, de maneira não muito diferente de como os vários livros da coleção podem se correlacionar.

Em paralelo com a forma como Roberto Calasso entende que a elaboração dos textos que acompanham o livro (capa, orelhas, às vezes

\footnotetext{
1 “O outro", em alemão, sendo o gênero neutro - em oposição a Der Andere, que seria masculino.
} 
apresentação) é função da editora, foi o diretor da Âyiné quem preparou as orelhas deste livro. Neste caso, em especial, o livro de Calasso de 2014, L'impronta dell'editore, foi traduzido para a língua portuguesa por Pedro Fonseca, o editor da Âyiné.

Calasso é conhecido pelo seu trabalho como escritor, tradutor, ensaísta e editor da Adelphi (desde os 21 anos de idade). Como revela em entrevista concedida a The Paris Review, em 2012, Calasso esteve desde cedo rodeado de livros - e se tornou um reconhecido colecionador de obras. Visceralmente ligado ao livro em posições distintas (leitor, autor, tradutor, editor), neste livro, o autor transita entre diversos universos editoriais - cada qual com sua marca.

O sumário de $A$ marca do editor apresenta conjuntos de textos dispostos em quatro blocos. O primeiro bloco conta com apenas um (longo) ensaio sobre a filosofia da editora que Calasso representa: livros únicos. Ler, escolher e preparar livros são tarefas que fazem parte da rotina de qualquer editor, mas o que deixa na editora "a marca do editor" são projetos mais abstratos. Livros únicos são, para Calasso (2020, p. 14), resultados de um salto. Um romance de alguém que não escreve romances, uma experiência marcante depositada por escrito, livros que não deixam rastros. Um catálogo de livros únicos seria um catálogo em que cada obra representa um elo de uma mesma corrente, um segmento de uma serpente de livros (CALASSO, 2020, p. 86). Esta organicidade entre os livros tem em sua origem a concepção de editoração como "dar forma" a um texto. Aldo Manúcio, ${ }^{2}$ inaugurador da tradição editorial italiana, publicou primeiro um livro único, de autor desconhecido, em linguagem híbrida, ilustrado e da ordem do não repetível. A capa, a diagramação, os tipos, os sinais e a epístola levam a assinatura do editor. Sua segunda publicação, uma edição de Sófocles, foi no formato de livro de bolso, ou seja, a forma como o livro é apresentado diz respeito ao trabalho do editor. Se lembrarmos de Ulises Carrión (2011, p. 14), "na velha arte o escritor não se julga responsável pelo livro. Ele escreve o texto. O resto é feito pelos empregados, os artesãos, os trabalhadores, os outros”. No caso de Manúcio: o editor. Carrión (2011, p. 15) define: "fazer um livro

\footnotetext{
${ }^{2}$ Conhecido na literatura sobre sinais de pontuação como Aldus Manutius, este editor, compositor e impressor de Veneza introduziu, de forma coerente, o ponto, a vírgula, dois pontos, ponto e vírgula e o ponto de interrogação no sistema de escrita como sinais sintáticos de pontuação (KRAHN, 2014, p. 53).
} 
é perceber sua sequência ideal de espaço-tempo por meio da criação de uma sequência paralela de signos, sejam linguísticos ou não".

No segundo bloco, em que a edição é contemplada como o gênero literário, o autor segue o raciocínio: encadear os livros publicados por uma editora implica ter recusado tantos outros. A escolha dos livros é guiada por razões difusas, particulares do editor (algo como seu gosto), e pela política editorial da editora que claramente exclui de seu catálogo certas possibilidades e assim demarca seu perfil.

No terceiro bloco, Calasso (2020, p. 130) traça breves retratos de editores (principalmente do continente europeu) e dá mostras das funções que esses editores assumiram em seu ofício: "Um intelectual e um aventureiro, um industrial e um déspota, um enganador e um homem invisível, um visionário e um pragmático, um artesão e um político". Os editores que Calasso toma como referência são notadamente editores literários: Aldo Manúcio, Kurt Wolff, ${ }^{3}$ Luciano Foà (também da Adelphi), Giulio Einaudi, ${ }^{4}$ Vladimir Dimitrijević, ${ }^{5}$ Peter Suhrkamp ${ }^{6}$ e Roger Strauss, ${ }^{7}$ que dialogaram com seus autores, incentivaram publicações e revelaram gênios (alcunha comumente reservada a Max Perkins ${ }^{8}$ que Calasso ignora neste livro, bem como passa ao largo do universo editorial anglo-saxão).

No último bloco, o autor retoma alguns pontos presentes no primeiro ensaio do livro e se concentra na figura do editor em contraste

\footnotetext{
${ }^{3}$ Alemão, judeu, reconhecido por apoiar escritores jovens e desconhecidos. Atuou em Leipzig no Kurt Wolff Verlag de 1931 a 1940 e depois imigrou para Nova Iorque, onde fundou a Pantheon Books. Alguns dos autores (Robert Walser, Franz Kafka, Georg Trakl) publicados pelo editor foram consagrados.

${ }^{4}$ Italiano, reconhecido por publicar autores antifascistas e por traduzir obras relevantes no cenário internacional (Brecht, Sartre, Mann, Borges etc.) pela Einaudi Editore.

${ }^{5}$ Jugoslavo radicado na Suíça, reconhecido pela publicação de autores eslavos como Óssip Mandelstam, Wassili Grossman e Karel Capek pela editora L'Age d'Homme. ${ }^{6}$ Alemão, atuou na editora Fischer e depois fundou a editora Suhrkamp. Autor, tradutor e ensaísta, é reconhecido por Calasso (2020, p. 130) como "o único que inventou uma editora depois da Segunda Guerra Mundial": a Escola de Frankfurt foi publicada por Suhrkamp. ${ }^{7}$ Americano, judeu, atuou na Farrar, Strauss and Giroux (FSG) e publicou autores como Joseph Brodsky, Alexander Soljenítsin, T. S. Eliot, Robert Lowell e Philip Roth, entre outros.

${ }^{8}$ Americano, atuou na Scribner's por quase 30 anos e é reconhecido por identificar e estimular grandes talentos da literatura americana (por exemplo Hemingway, Fitzgerald, Tom Wolfe), segundo Berg (2014).
} 
com as pressões do universo eletrônico, do mercado editorial e da indústria do livro. A informática, por exemplo, oferece outros suportes e formatos de livro, abrindo caminho para o self publishing e oferece dispersão e infinitude de textos. Todos esses elementos estão no polo oposto do editor que faz juízos, que seleciona e organiza (em séries, coleções) o que deve ser publicado. O editor que deixa a sua marca na editora, que constrói seu perfil editorial, está em oposição às editoras que publicam de tudo (porque publicar livros é também uma atividade comercial). "Mas não existe marca que não se fundamente em uma nítida, precisa seletividade e idiossincrasia das escolhas. Do contrário, a força da marca não consegue ser elaborada e se desenvolver" (CALASSO, 2020, p. 152). No último capítulo, mostra como publisher e manager editorial atuam em contraposição ao editor que artesanalmente compõe um repertório de expressividades latentes que ganham uma nova projeção.

Depois do último ponto final do texto que compõe o miolo do livro, o leitor se depara com uma "Nota aos textos", em que os locais de publicação (jornais, prefácio) e o modo de publicação (conferência, discurso) dos capítulos que compõem o livro são listados. O leitor atento percebe que muito pouco deste livro é inédito e entende que a edição é o método de escrita adotado por Roberto Calasso nesta obra: escrever o livro é editá-lo, compor, com fragmentos, um texto coeso (ordenado em blocos temáticos, seguindo uma sequência).

Duas palavras que Dimitrijević usou para definir o ofício de editor nos ajudam a apreciar esta edição de $A$ marca do editor: barqueiro e jardineiro. "Tanto o barqueiro quanto o jardineiro aludem a algo que preexiste: um jardim ou um viajante a ser transportado. [...] E aquilo que admiro em Dimitrijević é também sua relação com aquilo que está escondido e com aquilo que se mostra" (CALASSO, 2020, p. 134-135). Cultivar um jardim significa, entre outras coisas, dar visibilidade a certas composições. Conduzir um viajante significa, entre outras coisas, mostrar o caminho. Pedro Fonseca não optou por notas de rodapé que explicitassem a origem de cada capítulo do livro: escondeu as notas no fim. Talvez uma edição crítica, em que notas de rodapé formam o aparato explicativo de trajetórias editoriais e respectivos contextos históricos e políticos, autores, obras e casas editoriais fosse uma escolha mais acertada para conduzir o leitor brasileiro nessa flanagem por distintas "casas de máquina" do livro como objeto multidimensional. 


\section{Referências}

BERG, Andrew Scott. Max Perkins: um editor de gênios. Tradução de Regina Lyra. Rio de Janeiro: Intrínseca, 2014.

CALASSO, Roberto. Roberto Calasso, The Art of Fiction, no. 217. [Interviewed by] Lila Azam Zanganeh. The Paris Review, ed. 202, fall 2012. Disponível em: https://www.theparisreview.org/interviews/6168/ the-art-of-fiction-no-217-roberto-calasso. Acesso em: 4 jan. 2021.

CARRIÓN, Ulises. A nova arte de fazer livros. Belo Horizonte: C/Arte, 2011.

GEISER, Julia. Julia Geiser: a arte das capas de livros. [Entrevista cedida a] Voz da Literatura, [S. l.], 21 dez. 2018. Disponível em: https://www. vozdaliteratura.com/post/julia-geiser-a-arte-das-capas-de-livros. Acesso em: 4 jan. 2021.

KRAHN, Albert Edward. A New Paradigm for Punctuation. 2014. Dissertation (Doctor of Philosophy in Linguistics) - University of Wisconsin-Milwaukee, Milwaukee, 2014.

Recebido em: 4 de janeiro de 2021.

Aprovado em: 7 de abril de 2021. 